\title{
ДИАГНОСТИКА РАЗВИТИЯ РОССИЙСКИХ МЕЖДУНАРОДНЫХ НЕФТЕДОБЫВАЮЩИХ КОРПОРАЦИЙ НА ОСНОВЕ СИСТЕМЫ ПОКАЗАТЕЛЕЙ ЭФФЕКТИВНОСТИ
}

\author{
(c) 2021 Кашбразиев Ринас Васимович \\ доктор экономических наук, доцент \\ Казанский (Приволжский) федеральный университет, Россия, Казань \\ E-mail: rkashbra@gmail.com \\ (c) 2021 Аль-чабави Мохаммед Ради Мухесин \\ Соискатель \\ Казанский (Приволжский) федеральный университет, Россия, Казань \\ E-mail:m_radi84@yahoo.com
}

Глобализация мировой экономики, открытие границ национальных экономических рынков, стремление сильных государств упрочить свои позиции, нарастить объёмы ресурсов порождает такое явление как глобальная конкуренция. В статье выделяются фундаментальные факторы, определяющие характер и содержание конкурентных стратегий нефтедобывающих компаний мира. Раскрыты основные факторы трансформации стратегий нефтедобывающих компаний в современных условиях. Показано влияние фактора изменения цен на нефть. Раскрыто содержание геополитического влияния на трансформацию стратегий нефтяных компаний. Определены перспективы трансформации стратегий в связи с общесистемным кризисом мировой экономики. Также, исходя из исследования можно сказать, что наиболее важное значение в деятельности современных ТНК, в условиях повышения глобальной конкуренции приобретают маркетинговые и инвестиционные стратегии.

Ключевые слова: стратегия, нефтяные компании, корпорации, нефтедобывающие корпорации, трансформация.

В теории стратегического менеджмента существуют различные способы определения понятия «глобальная конкуренция». В частности, под глобальной конкуренцией могут понимать:

Разработка и реализация корпоративных, бизнес- и функциональных стратегий современных международных нефтедобывающих корпораций на основе применения инструментов стратегического менеджмента с учётом повышения глобальной конкуренции связана с затратой значимых объёмов финансовых ресурсов. Повышение глобальной конкуренции, к примеру, становится одним из факторов, подталкивающих транснациональные нефтегазовые компании к привлечению услуг крупнейших мировых консалтинговых компаний, специализирующихся в сфере стратегического планирования (Accenture, Bain and Co., Booz, A.T.Kearney, McKinsey, The Boston Consulting Group и др.).

Привлечение внешних консультантов связано со многими недостатками, одним из главных среди которых является высокая стоимость их услуг, доходящая до нескольких сотен тысяч долларов [3]. Разработка стратегий развития нефте-

добывающих компаний собственными силами также чревата существенными затратами, которые не имеют прямого характера (не отражаясь в статьях расходов компании), но заключены в затратах труда и его оплате специалистов, задействованных в разработке стратегий, в возможных потерях в результате стратегических ошибок и проч. Ещё более существенны затраты при реализации стратегий развития нефтедобывающих компаний и практическом использовании инструментов стратегического менеджмента.

Таким образом, ресурсоемкость стратегического управления нефтедобывающих корпораций делает необходимым оценку эффективности применяемых инструментов стратегического менеджмента. Важно оговориться, что применение инструментов стратегического менеджмента нефтяных корпораций оказывает прямое влияние на эффективность всех аспектов их деятельности. Именно поэтому происходит методическое «слияние» оценки эффективности применения инструментов стратегического менеджмента и общей оценки эффективности 
деятельности международных нефтяных корпораций.

В результате эволюции развития современных нефтедобывающих компаний, практически все крупнейшие международные нефтегазовые корпорации являются вертикально-интегрированными. Таким образом, в рамках субъекта хозяйствования рынка нефти и нефтепродуктов действует, по существу, несколько, объединенных едиными корпоративными целями организаций разного профиля. Этот факт также влияет на формирование системы показателей оценки эффективности инструментов стратегического менеджмента современных нефтедобывающих компаний.

Кроме того, процесс развития международных нефтедобывающих организаций сопровождался в соответствии с ростом глобальной конкуренции усложнением подходов и содержания системы показателей оценки эффективности инструментария стратегического менеджмента.

В практике деятельности крупнейших российских и зарубежных международных нефтедобывающих компаний может применяться до 100 различных показателей, каждый из которых в том или ином ракурсе выражает эффектив- ность выбранных инструментов стратегического управления.

Отметим также, что подходы к структурированию показателей эффективности российских и зарубежных международных нефтедобывающих компаний также имеют значимые различия. Так, российские международные нефтедобывающие компании используют традиционную градацию показателей, разбивая их на бизнессегменты: бизнес-сегмент «разведка, запасы и добыча»; бизнес-сегмент «нефтепереработка и нефтехимия»; бизнес-сегмент «реализация продукции»; состояние стратегических финансовых показателей деятельности.

Зарубежные нефтедобывающие компании, оперирующие на различных национальных рынках, используют несколько иной подход, разделяя показатели эффективности на две группы: Upstream (разведка и добыча) и Downstream (нефтехимия и нефтепереработка).

Используемые в практике формирования крупнейших мировых нефтедобывающих компаний показатели эффективности, включаемые ими в систему сбалансированных показателей, можно классифицировать по следующим основаниям (Рисунок 1).

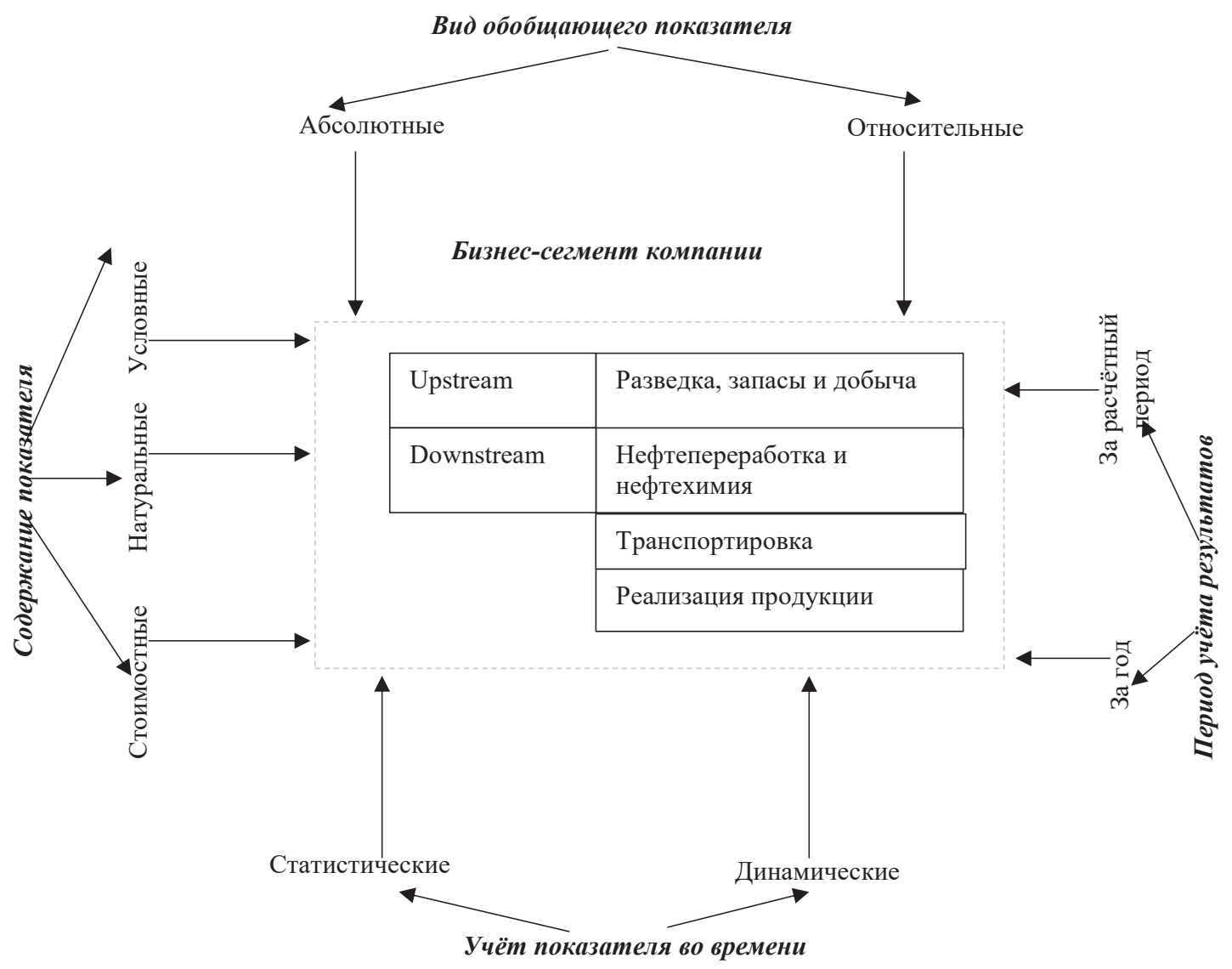

Рисунок 1. Классификация системы показателей эффективности, используемых в практике деятельности международных нефтедобывающих компаний 
Развитие нефтедобывающих компаний в условиях повышения глобальной конкуренции обусловило состояние подходов к оценке эффективности инструментов стратегического менеджмента не только на прикладном, но и на теоретическом уровне.

Выделяемые исследователями показатели эффективности инструментария стратегического управления можно отнести к общим количественным показателям. K характерным для большинства практических и теоретических подходов к конструированию показателей эффективности нефтедобывающей компании можно отнести недостаточное внимание к показателям внешнеторговой деятельности (по осуществлению операций прямого экспорта и, так называемых, «международных продаж» - то есть реализации продукции с территории других стран, в которых присутствуют только дочерние компании корпорации, являющиеся нерезидентами таких стран), отсутствие специальных показателей, отражающих это направление нефтедобывающих компаний.

В связи с этим, общие количественные показатели современных международных компаний нефтяной индустрии, на наш взгляд, целе- сообразно представить в виде трехмерного поля показателей эффективности (Рисунок 2).

В соответствии с проведенным анализом практических и теоретических подходов к формированию системы показателей эффективности деятельности нефтяных транснациональных корпораций, предложенной классификацией системы показателей эффективности, используемых в практике деятельности международных нефтедобывающих компаний, авторским видением трехмерной структуры системы показателей эффективности применения инструментов развития международных нефтедобывающих корпорациях, нами предлагается следующий состав показателей оценки эффективности применения инструментов развития на примере ПАО «Газпром Нефть».

Кроме выделенных общих количественных показателей эффективности использования инструментов стратегического менеджмента, уместно также использовать специальные показатели эффективности. К таковым мы относим:

1. Экономическая результативность, рассчитываемая как (1):

$$
I_{e}=\frac{P_{z}+K_{z}}{P_{f r}+K_{f r}}
$$

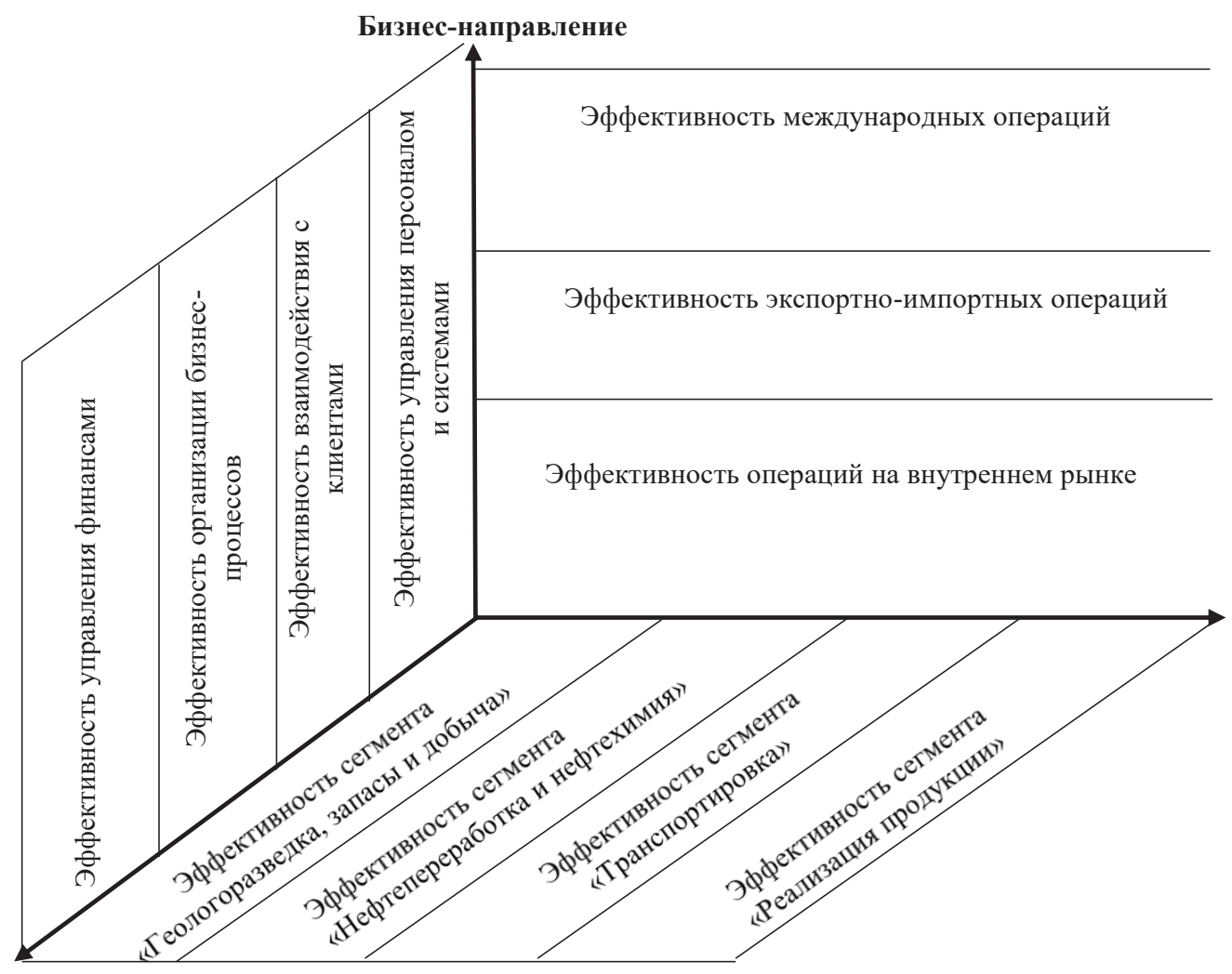

Бизнес-проекция

Бизнес--сегмент

Рисунок 2. Трехмерная структура системы показателей эффективности применения инструментов развития международных нефтедобывающих корпораций 
2. Адекватность сценарного планирования. Сценарное планирование, выражающееся в том числе в построении прогнозов состояния тех или иных показателей деятельности нефтедобывающих компаний становится в условиях повышения глобальной конкуренции одним из основных инструментов стратегического менеджмента. Ошибки в построении прогнозов оказывают негативное влияние на деятельность всей компании, поскольку в соответствии с прогнозами выделяются ресурсы на достижение стратегических целей развития. Данный показатель рассчитывается следующим образом (2):

$$
A_{f}=F_{f_{i}}-F_{p_{i}}
$$

При превышении фактических значений показателей над прогнозируемыми: а) для показателей, целевые значения которых стремятся к максимуму (выручка, прибыль, добыча, реализация и др.); б) для показателей, целевые значения которых стремятся к минимуму (чистый долг к рыночной капитализации, Gearing, доля краткосрочных кредитов и займов в общей сумме долга, общая сумма долга к EBITDA и др.).

Крупные международные корпорации нефтегазовой индустрии осуществляют свою де- ятельность, как правило, на основе нескольких бизнес-стратегий, что связано с соответствующим числом основных бизнес-сегментов в их деятельности. В связи с этим, возникает другая проблема - отбора наиболее значимых показателей эффективности, в совокупности позволяющих обеспечить адекватную оценку используемых инструментов стратегического менеджмента. Как было установлено выше, нефтедодывающие компании используют в своей деятельности до 80-100 показателей, тем или иным образом характеризующих эффективность их деятельности.

Вместе с тем, система показателей эффективности не должна перегружать пользователей информации сведениями, не относящимися непосредственно к анализируемым. В связи с этим, некоторые исследователи справедливо указывают на необходимость использования критериев при отборе показателей эффективности [5-6]. Однако, содержание требований к показателям в предыдущих исследованиях не вполне отвечает потребностям оценки эффективности инструментов стратегического менеджмента нефтедобывающих компаний.

Нами предлагаются следующие критерии отбора показателей эффективности (Таблица 1).

Таблица 1. Критерии отбора показателей эффективности инструментов стратегического менеджмента нефтедобывающих компаний

\begin{tabular}{|c|c|c|}
\hline № & Критерий & Содержание \\
\hline 1 & $\begin{array}{l}\text { Доступность показа- } \\
\text { теля }\end{array}$ & $\begin{array}{l}\text { Автоматизация контроллинга на нефтедобывающем предприятии на } \\
\text { основе использования современных информационно-технических средств } \\
\text { и программного обеспечения для получения показателей субъектами стра- } \\
\text { тегического управления в необходимые сроки. }\end{array}$ \\
\hline 2 & $\begin{array}{l}\text { Информативность } \\
\text { показателя }\end{array}$ & $\begin{array}{l}\text { Показатель в полной мере удовлетворяет информационно-управленческие } \\
\text { потребности субъектов принятия решений }\end{array}$ \\
\hline 3 & Измеримость & Показатель может быть оценен количественно \\
\hline 4 & $\begin{array}{l}\text { Соответствие приня- } \\
\text { тым единицам изме-- } \\
\text { рения }\end{array}$ & $\begin{array}{l}\text { Стоимостные, натуральные и условные показатели соответствуют обще- } \\
\text { принятым стандартам конструирования индикаторов эффективности в } \\
\text { нефтедобывающих компаниях }\end{array}$ \\
\hline 5 & $\begin{array}{l}\text { Ресурсная рациональ- } \\
\text { ность (экономичность) }\end{array}$ & $\begin{array}{l}\text { Затраты времени труда работников на получение отчётов по показателям } \\
\text { минимальны }\end{array}$ \\
\hline 6 & $\begin{array}{l}\text { Сопоставимость пока- } \\
\text { зателя с плановыми }\end{array}$ & $\begin{array}{l}\text { Возможность сопоставления показателя с внутренними плановыми пока- } \\
\text { зателями и значениями за предыдущие годы }\end{array}$ \\
\hline 7 & $\begin{array}{l}\text { Сопоставимость пока- } \\
\text { зателя с отраслевыми }\end{array}$ & $\begin{array}{l}\text { Возможность сопоставления показателя со средними отраслевыми значе- } \\
\text { ниями выбранного показателя в деятельности нефтедобывающих компа- } \\
\text { ний. }\end{array}$ \\
\hline 8 & Значимость показателя & $\begin{array}{l}\text { Показатель должен представлять ценность с точки зрения его влияния } \\
\text { (прямого) на сформулированные стратегические задачи нефтедобываю- } \\
\text { щей компании }\end{array}$ \\
\hline 9 & $\begin{array}{l}\text { Уникальность показа- } \\
\text { теля }\end{array}$ & $\begin{array}{l}\text { Показатель отражает определенную уникальную характеристику эффек- } \\
\text { тивности инструмента стратегического менеджмента, не дублируя другие } \\
\text { показатели }\end{array}$ \\
\hline
\end{tabular}


Учитывая вышесказанное, в работе разработан алгоритм оценки эффективности применения инструментов развития международных нефтедобывающих корпорациях в условиях повышения глобальной конкуренции.

Отбор каждого показателя эффективности осуществляется, во-первых, с учётом веса конкретного критерия (определяется экспертным путём) и, во-вторых, на основе оценки целесообразности включения показателя путём балльной оценки лиц, принимающих решения.

\section{Библиографический список}

1. Андреева T. А. Тенденции развития стратегического управления // Вопросы современной науки и практики. Университет им. В. И. Вернадского.-2012.- № 3.- С. 146-153.

2. Данько Т. П. Менеджмент и маркетинг, ориентированный на стоимость: Учебник.- М.: ИНФРА-М, 2014.$416 \mathrm{c.}$

3. Козняшев К. А. Стратегии развития вертикально-интегрированных нефтяных компаний в условиях нового мирового энергетического порядка: дис. ... канд. экон. наук: 08.00.14 / Козеняшев Кирилл Андреевич. - Москва, 2016.- 181 с.

4. Мусина Д.Р. Формирование системы логистического контроллинга в буровой компании [Электронный ресурс] // Электронный научный журнал «Нефтегазовое дело». 2015. № 4, С. 549-563.

5. Тасмуханова А.Е., Кулембетова А. Р., Мусина Д. Р. Стратегический контроллинг с применением системы сбалансированных показателей в нефтяных компаниях [Электронный ресурс] // Интернет-журнал «Науковедение» Том 8, № 4 (2016). URL - http://naukovedenie.ru/PDF/75EVN416.pdf (дата обращения 10.04.2020).

6. Казакова Н.А., Хлевная Е.А., ЦветковаЛ.К. Оперативный и стратегический контроллинг в холдингах // Вестник финансового университета. № 1 (91), 2016. С. 47-57.

7. Пирс П.Д. Стратегический менеджмент.-СПб.: Питер, 2013.-560 с.

8. Фахрутдинова Е.В., РоднянскийД.В. Анализ энергетических кластеров и их влияния на социальноэкономическое развитие России// Экономические науки. 2016. № 142. С.26-29.

9. Фахрутдинова Е. В. Вопросы теории управления проектами// Экономические науки. 2009. № 52. С.134-138.

10. Gianni S., Jemth P. Affinity versus specificity in coupled binding and folding reactions // Protein Engineering, Design and Selection. - 2019.- Volume 32, Issue 8. - Pp. 355-357.

11. Tosheva E., Dimeski B. The competition policy in western balkan countries: How far they have come on the EU accession “Road?" // Balkan Social Science Review. - 2019._- Volume 14, Issue 14.- Pp. 31-35.

12. De Giovanni P. When feature-based production capabilities challenge operations: Drivers, moderators, and performance // International Journal of Operations and Production Management. - 2019. - Volume 40, Issue 2.Pp. 221-242.

13. Zhuravleva N., Guliy I., Shavshukov V. Simulation modeling of changes in demand for rail transportation // IOP Conference Series: Earth and Environmental Science. - 2019._- Volume 403, Issue 1. - № 012230.

14. Grassi B., Sauvagnat J. Production networks and economic policy // Oxford Review of Economic Policy.- 2019.Volume 35, Issue 4.- Pp. 638-677. 